Research Paper

\title{
Relationship between the Metabolic Associated Fatty Liver Disease and Endometrial Thickness in Postmenopausal Women: A Cross-sectional Study in China
}

\author{
Jia-ying Wei ${ }^{*}$, Zhou $\mathrm{Xu}^{1,2^{*}}$, Hao $\mathrm{Li}^{1^{*}}$, Wen-qin $\mathrm{Du}^{3}$, Bai-ling $\mathrm{Niu}^{4}$, Shu $\mathrm{Li}^{1}$, Shen Tian ${ }^{1}$, Juan $\mathrm{Wu}^{1}$, Yu-ling

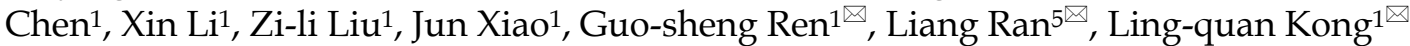 \\ 1. Department of Endocrine and Breast Surgery, The First Affiliated Hospital of Chongqing Medical University, Chongqing 400016, China. \\ 2. Department of Thyroid and Breast Surgery, Affiliated Hospital of North Sichuan Medical College, Nanchong, Sichuan 637000, China. \\ 3. Department of Statistics, Colorado State University, Fort Collins, Colorado 80523, USA. \\ 4. Department of Intensive Care Medicine, The First Affiliated Hospital of Chongqing Medical University, Chongqing 400016, China. \\ 5. The Health Management Center of the First Affiliated Hospital of Chongqing Medical University, Chongqing 400016, China. \\ *These authors have contributed equally to this work.
}

$\triangle$ Corresponding authors: Dr. Ling-quan Kong, Department of Endocrine and Breast Surgery, the First Affiliated Hospital of Chongqing Medical University, Chongqing 400016, China. E-mail: huihuikp@163.com; Tel.: +8613101380893; Liang Ran, The Health Management Center of the First Affiliated Hospital of Chongqing Medical University. E-mail: ranhaocun@163.com. Dr. Guo-sheng Ren, Department of Endocrine and Breast Surgery, the First Affiliated Hospital of Chongqing Medical University, Chongqing 400016, China. E-mail: rengs726@163.com.

(c) The author(s). This is an open access article distributed under the terms of the Creative Commons Attribution License (https://creativecommons.org/licenses/by/4.0/). See http://ivyspring.com/terms for full terms and conditions.

Received: 2021.03.23; Accepted: 2021.06.09; Published: 2021.06.22

\begin{abstract}
Objectives: To determine the relationship between the endometrial thickness (ET) and metabolic associated fatty liver disease (MAFLD) in the postmenopausal women who have a comprehensive health examination.

Methods: This was a population-based, retrospective observational study of the prevalence of MAFLD in 8594 postmenopausal women with different ET in the Quality Control Center of Health Examination in Chongqing, China. Binary and multivariable logistic regression analyses were used to obtain odds ratios and $95 \%$ confidence intervals for patients of different ET with MAFLD after adjusting for age.

Results: The incidences of MAFLD were $28.6 \%$ (1352), 30.3\% (1058), 34.9\% (133) in postmenopausal women with ET of $<3 \mathrm{~mm}, 3 \mathrm{~mm} \leq \&<5 \mathrm{~mm}$, and $\geq 5 \mathrm{~mm}$, respectively. Compared with a baseline ET of less than 5.0 $\mathrm{mm}$, the risk of MAFLD in patients with $\mathrm{ET}$ of $\geq 5.0 \mathrm{~mm}$ is higher $(\mathrm{OR}=1.291,95 \% \mathrm{Cl}$ : $1.041-1.603, \mathrm{P}<0.05)$. After adjustment for age, a statistically significant positive correlation was still observed. The increased prevalence of MAFLD in patients with ET of $3 \mathrm{~mm} \leq \&<5 \mathrm{~mm}(\mathrm{OR}=1.110,95 \% \mathrm{Cl}$ : 1.008-1.223) and $\geq 5 \mathrm{~mm}$ $(\mathrm{OR}=1.383,95 \% \mathrm{Cl}: 1.109-1.724)$ achieved statistical significance, respectively. In addition, multiple logistic analyses controlling for age also confirmed the finding of positive correlation among body mass index (BMI) and ET.

Conclusion: Our results suggest that there is a positive correlation between MAFLD and ET in postmenopausal women. In addition, increased BMI is also associated with an increased risk of thickened endometrium.
\end{abstract}

Key words: Metabolic associated fatty liver disease, body mass index, endometrial thickness, postmenopausal women, ultrasonography

\section{Introduction}

Nonalcoholic fatty liver disease (NAFLD), defined as the fat infiltration into liver, is now recognized as one of the most common causes of chronic liver disease in the developed world [1]. It is estimated that the global prevalence rate of NAFLD in the general population is $24 \%-25.2 \%$, which may put more pressure on the healthcare system [2]. Also,
NAFLD is a type of metabolic stress-induced liver damage closely related to metabolic syndrome. Recently, the concept of metabolic associated fatty liver disease (MAFLD) has been proposed to provide a better understanding of potential liver dysfunction in metabolic diseases by an international expert consensus statement [3-6]. The proposed MAFLD can 
eliminate the potential impact of other chronic liver diseases and excessive drinking on the diagnosis [7-11]. In addition, to determine fatty liver disease (FLD) prevalence in the general population, ultrasound evaluation is also the most widely used first-line diagnostic modality [12]. As it is relatively inexpensive and has good estimated sensitivity $(85 \%)$ and specificity $(94 \%)$ for diagnosing moderate to severe steatosis [13]. The Asian Pacific Association for the Study of the Liver (APASL) clinical practice guidelines recommended using abdominal ultrasound, a non-invasive tool, for the diagnosis of MAFLD [14].

Endometrial carcinoma is one of the most common gynecological cancers in women [15] and is closely related to hormone levels [1,16,17]. Its incidence rate and mortality are increasing each year all over the world, especially in industrialized countries, which are estimated at about 76000 death in 2019 [18]. Depending on the American College of Obstetrics and Gynecology (ACOG) 2018 [19], ultrasonography is a general and sensitive detection method of endometrial cancer. A review of approximately 2,900 postmenopausal women demonstrated that the sensitivity and specificity of ultrasound diagnosis of endometrial thickness (ET) of $5 \mathrm{~mm}$ are $90 \%$ and $54 \%$, respectively for the detection of endometrial cancer [12]. Postmenopausal women who underwent annual pelvic ultrasound screening are the most important detection method for endometrial cancer. ET over $5 \mathrm{~mm}$ was most likely to be defined as endometrial thickening [20-24] and study shows that the risk of endometrial cancer and endometrial hyperplasia with atypia in asymptomatic postmenopausal women is increased with ET $\geq 11$ $\mathrm{mm}$ [25]. ET of postmenopausal women is related to endometrial disease-related carcinoma [26,27].

Clinical researches verified the progression of FLD in advanced fibrosis [28], hepatocellular carcinoma [29] and even extrahepatic malignancy include endometrial cancer [30]. Two recent studies have demonstrated that women with endometrial cancer have a significantly increased risk of NAFLD $[1,31]$. That is to say, they may have the same underlying molecular mechanisms [1]. However, there is actually no research on MAFLD [32] and ET in postmenopausal women, and the relationship between these two parameters is still unclear.

In China, asymptomatic women undergoing regular health check-ups usually chose to accept both abdominal and pelvic ultrasonography [17]. So, we can do further investigations. The purpose of this study was to investigate the relationship between MAFLD and ET in the asymptomatic postmenopausal women.

\section{Material and methods}

\section{Population}

We obtained data from the Public Health Center of the First Affiliated Hospital of Chongqing Medical University (a large tertiary hospital in southwest China) which contains comprehensive information of the female population who underwent comprehensive health examination, including age, height, BMI, waist circumference, metabolic components, and abdominal and gynecological ultrasonography imaging findings. This was a population-based, retrospective observational study of the prevalence of MAFLD investigated in consecutive postmenopausal women who underwent comprehensive health examination and accepted both abdominal and gynecological ultrasonography evaluation in the Quality Control Center of Health Examination in Chongqing, China, from January 2015 to July 2018. The characteristics of all examinees presenting with different ET were analyzed.

The ET of all participants was accurately determined by a $4-8 \mathrm{MHz}$ vaginal transducer (HD11XE; Philips Medical Systems) or a 4-11 MHz transducer (Aplio 500; Canon Medical Systems), and then was routinely evaluated and recorded [33]. As transvaginal sonography, the bladder was emptied at first, patients were examined in a lithotomy position scanned with an intravaginal ultrasound probe. The upper abdomen transabdominal ultrasound was scanned in the supine position with bladder filling. Scans were performed by sonographers with the same level of knowledge all came from the Department of Ultrasonography of the First Affiliated Hospital of Chongqing Medical University. All ultrasound scans were saved in the hard drive of the machine in digital imaging and communications in medicine format.

The data were collected and registered in the electronic medical record system of the Quality Control Center of Health Examination in Chongqing [33]. Basic information such as age, gender, disease history, and postoperative ultrasound description was included. Anthropometric parameters such as blood pressure, weight, height, and waist circumference were measured by allied health professionals according to standard methods. Moreover, the blood samples of metabolic components were collected after fasting for at least 8 hours and analyzed in the laboratory of the First Affiliated Hospital of Chongqing Medical University certified by the College of American Pathologists (CAP Number: 7215494) [33]. The study was approved and supervised by the Ethics Committee of The First Affiliated Hospital of Chongqing Medical University. 


\section{Inclusion and Exclusion Criteria}

We included 50897 women who underwent comprehensive health examination in the Quality Control Center of Health Examination in Chongqing, China, from January 2015 to July 2018(the health examiners are consecutive). Then excluded those who had a hysterectomy, cholecystectomy [34-36], ovariectomy $[37,38]$ or a history of relative malignancy, intrauterine device in situ or if they were during pregnant, puerperium periods or breast feeding [39]. Also, the cases without the original descriptions and detailed reports of abdominal and gynecological ultrasonography (include ET) or without available data of age, weight, height, body mass index, or correlated metabolic components [40] were ruled out. Finally, 8594 postmenopausal women were enrolled in this study.

\section{Statistical analysis}

The postmenopausal women were divided into three groups: (1) the postmenopausal women with ET of $<3 \mathrm{~mm}$ (2) the postmenopausal women with ET of 3 $\mathrm{mm} \leq \&<5 \mathrm{~mm}$ and (3) the postmenopausal women with ET of $\geq 5 \mathrm{~mm}$ (the cutoff threshold for ET has been used in previous studies [20-24]). Statistical analysis was performed with Microsoft Excel 2013, SPSS 23.0, and R software in this study. $\mathrm{P}$ value of $<0.05$ was considered to be statistically significant. All data were analyzed according to the intention-to-treat principle. Mean [std. deviation] and number (percentage) were used to describe demographic and clinical data. Kruskal Wallis test and Chi-square test were used to compare subject characteristics and determine consistency. Multivariable and binary

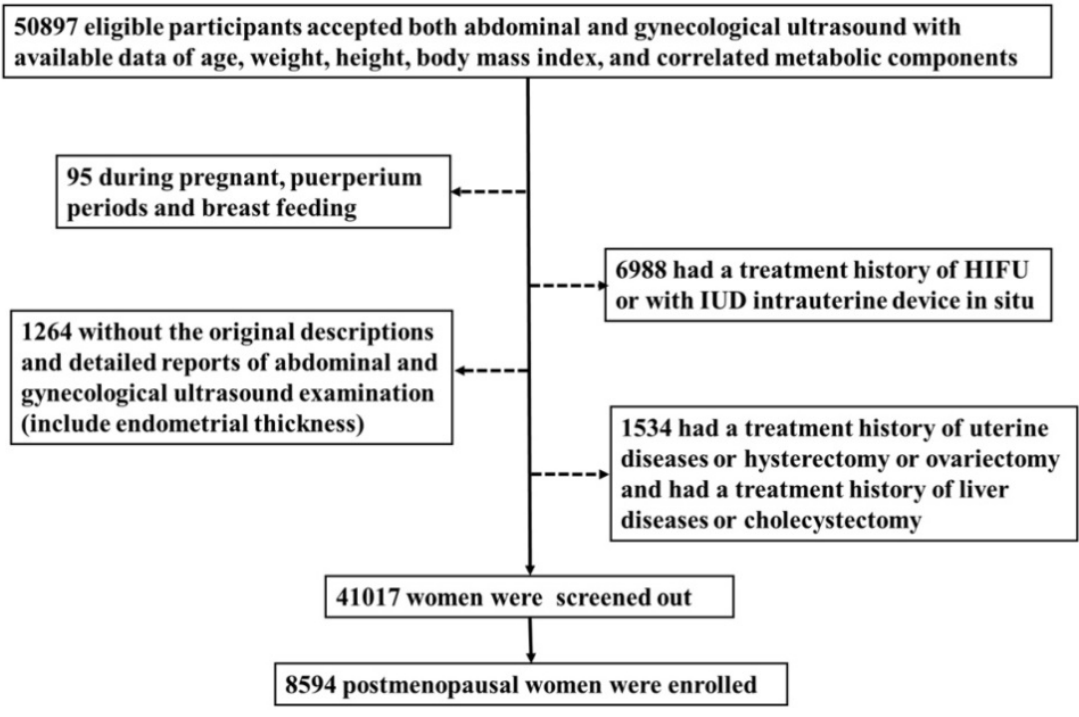

Figure 1. Flow chart of study participants. A total of 50897 women participated in this study of whom 8594 were postmenopausal. Among the postmenopausal women, $381(4.4 \%)$ had an ET greater than or equal to $5 \mathrm{~mm}$, of whom $137(36.0 \%)$ presented with fatty liver based on transabdominal ultrasonography and 133 (34.9\%) presented with MAFLD.

\section{Results}

logistic regression analyses were used to obtain odds ratios and $95 \%$ confidence intervals for patients of different ET with FLD after adjusting for age.

A total of 50897 women participated in this study of whom 8594 were postmenopausal (Figure 1). Among the postmenopausal women, $381(4.4 \%)$ had an ET greater than or equal to $5 \mathrm{~mm}$, of whom 137 $(36.0 \%)$ presented with fatty liver based on transabdominal ultrasonography and 133 (34.9\%) presented with MAFLD. The diagnostic criteria of MAFLD are based on evidence of hepatic steatosis (Figure 2), in addition to one of the following three criteria, namely overweight/obesity, presence of type 2 diabetes mellitus, or evidence of metabolic dysregulation [3] which was defined as having at least two of the following; (1) waist circumference $\geq 90 \mathrm{~cm}$ (Asian male), $\geq 80 \mathrm{~cm}$ (Asian female), (2) triglyceride $\geq 1.70 \mathrm{mmol} / \mathrm{L}$ (or treated for dyslipidemia), (3) highdensity lipoprotein (HDL) $<1.0 \mathrm{mmol} / \mathrm{L}$ (male), $<1.3$ $\mathrm{mmol} / \mathrm{L}$ (female) (or treated for dyslipidemia), (4) blood pressure $\geq 130 / 85 \mathrm{mmHg}$ (or treated for hypertension), (5) fasting plasma glucose 5.6 to 6.9 $\mathrm{mmol} / \mathrm{L}$ or 2-h OGTT (1-h 75-g-oral glucose tolerance test (OGTT) $7.8 \mathrm{mmol} / \mathrm{L}$ or $\mathrm{HbA} 1 \mathrm{c} 5.7 \%$ to $6.4 \%$, (6) serum/plasma high-sensitivity $\mathrm{C}$ reactive protein level $>2 \mathrm{mg} / \mathrm{L}$, (7) homeostasis model assessment (HOMA) 2 was calculated to estimate insulin sensitivity and insulin resistance $\geq 2.5$. The ET (and age) predicting the presence of FLD were examined by the R (Figure 3 ).

The baseline characteristics of all participants with different ET are shown in Table 1. The postmenopausal women with ET of $\geq$ $5 \mathrm{~mm}$ were more likely to be overweight or obese, as well as have elevated waist circumference, blood pressure, triglycerides, fasting blood sugar, and reduced high-density lipoprotein cholesterol.

The results of women with abdominal and gynecological ultrasound imaging findings are shown in Table 2. If the expected frequency counts count less than 5, the chi-square test was conducted. There was a weak positive correlation between the prevalence of ultrasonic based fatty liver disease and different endometrial thickness. The prevalence of ultrasonic based fatty liver disease were $30.0 \%$ (1417), 31.7\% (1109), 36.0\% (137) in postmenopausal women with ET of less than $3 \mathrm{~mm}, 3$ 
$\mathrm{mm} \leq \&<5 \mathrm{~mm}$, and $\geq 5 \mathrm{~mm}$, respectively. While the incidences of MAFLD were $28.6 \%$ (1352), 30.3\% (1058), 34.9\% (133) in postmenopausal women with ET of $<3 \mathrm{~mm}, 3 \mathrm{~mm} \leq \&<5 \mathrm{~mm}$, and $\geq 5 \mathrm{~mm}$, respectively.
To evaluate the correlation between the FLD and ET (Table 3), the number of the postmenopausal women with endometrial thickness of less than $3 \mathrm{~mm}$ is 8213 , and the number of postmenopausal women with endometrial thickness of greater than or equal to

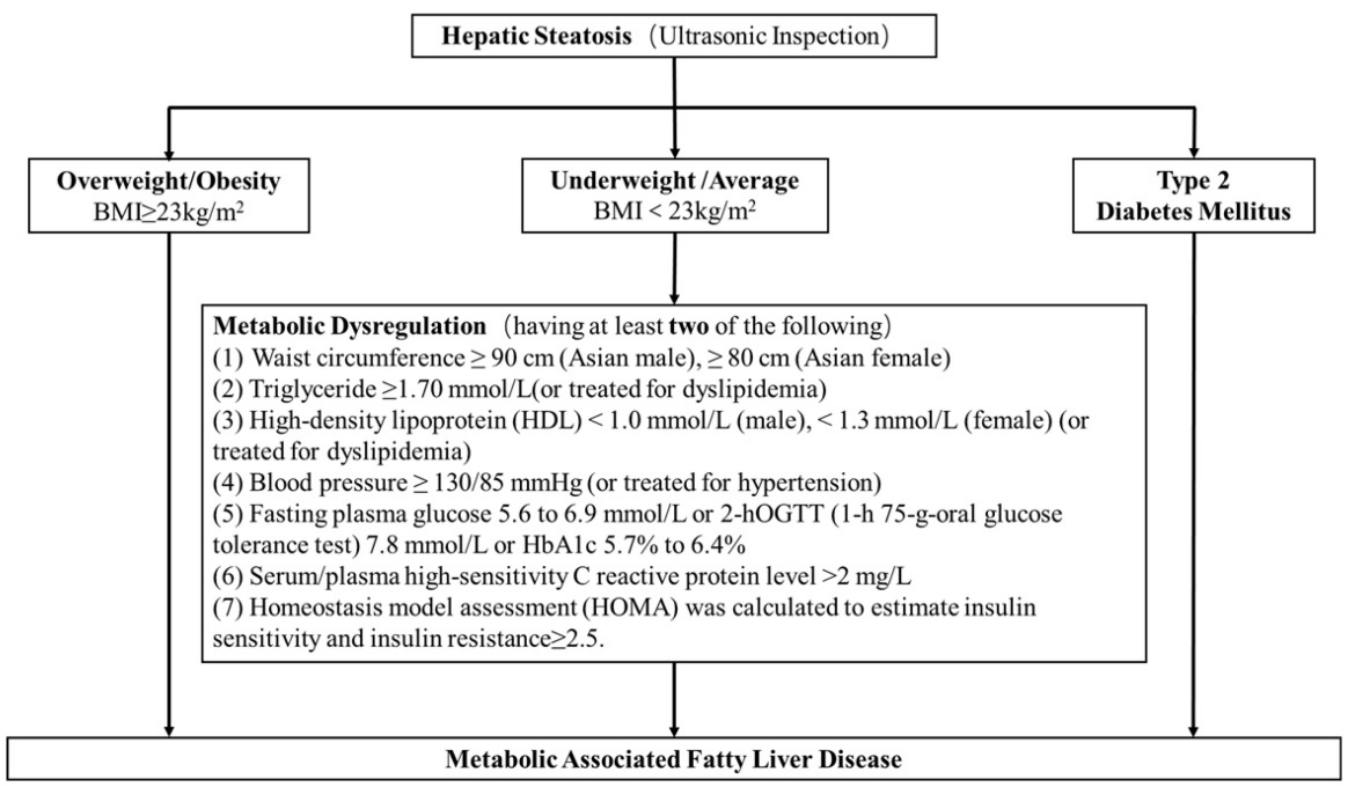

Figure 2. The diagnostic criteria of MAFLD. The diagnostic criteria of MAFLD are based on evidence of hepatic steatosis, one of the following three criteria, namely overweight/obesity, presence of type 2 diabetes mellitus, or evidence of metabolic dysregulation 3 which was defined as having at least two of the following; (1) waist circumference $\geq 90 \mathrm{~cm}$ (Asian male), $\geq 80 \mathrm{~cm}$ (Asian female), (2) triglyceride $\geq 1.70 \mathrm{mmol} / \mathrm{L}$ (or treated for dyslipidemia), (3) high-density lipoprotein ( $\mathrm{HDL}$ ) $<1.0 \mathrm{mmol} / \mathrm{L}$ (male), $<1.3 \mathrm{mmol} / \mathrm{L}$ (female) (or treated for dyslipidemia), (4) blood pressure $\geq 130 / 85 \mathrm{mmHg}$ (or treated for hypertension), (5) fasting plasma glucose 5.6 to $6.9 \mathrm{mmol} / \mathrm{L}$ or $2-\mathrm{h}$ OGTT (1-h 75-g-oral glucose tolerance test (OGTT) $7.8 \mathrm{mmol} / \mathrm{L}$ or HbAlc $5.7 \%$ to $6.4 \%$, (6) serum/plasma high-sensitivity $\mathrm{C}$ reactive protein level $>2 \mathrm{mg} / \mathrm{L}$, (7) homeostasis model assessment (HOMA) 2 was calculated to estimate insulin sensitivity and insulin resistance $\geq 2.5$.

\section{A}

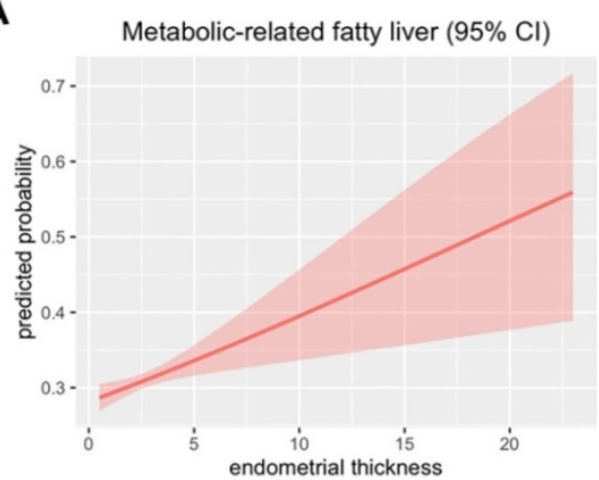

C

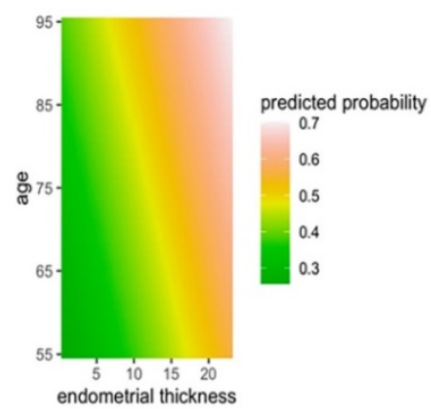

B

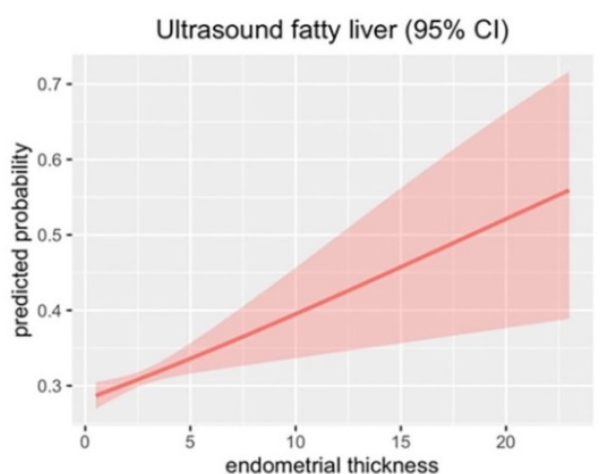

D

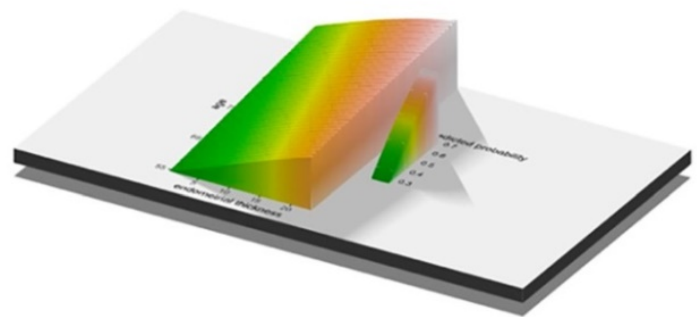

Figure 3. The predicted probability of metabolic associated fatty liver disease (MAFLD) and ultrasound based fatty liver disease. (A) The Endometrial thickness predicting the presence of Metabolic associated fatty liver disease were examined by the R. (B) The Endometrial thickness predicting the presence of Ultrasonic fatty liver were examined by the R. (C-D) The Endometrial thickness and age predicting the presence of FLD were examined by the R. 
Table 3. The odds ratio for metabolic associated fatty liver disease (MAFLD) and ultrasound-based fatty liver disease in relation to endometrial thickness

\begin{tabular}{|c|c|c|c|c|c|}
\hline \multirow{4}{*}{$\begin{array}{l}\text { Endometrial } \\
\text { thickness/mm }\end{array}$} & \multicolumn{5}{|l|}{ Liver status } \\
\hline & \multirow[t]{2}{*}{ Total $(n=8594)$} & Model 1 & & \multicolumn{2}{|l|}{ Model 2} \\
\hline & & \multicolumn{2}{|c|}{ Ultrasonic fatty liver $(+)(n=2663)$} & \multicolumn{2}{|c|}{ MAFLD $(+)(n=2543)$} \\
\hline & Number (\%) & OR $(95 \% C I)^{a}$ & $P$ value & OR $(95 \% \mathrm{CI})^{\mathrm{b}}$ & P value \\
\hline$<5$ & $8213(95.6 \%)$ & 1 (Reference) & 0.032 & 1 (Reference) & 0.020 \\
\hline$\geq 5$ & $381(4.4 \%)$ & $1.264(1.020-1.566)$ & & $1.291(1.041-1$ & \\
\hline
\end{tabular}

a. OR: odds ratio; $95 \% \mathrm{CI}$ : 95\% confidence interval.

b. The odds ratio of fatty liver disease is adjusting for nothing.

Table 4. Binary logistic regression analysis for metabolic associated fatty liver disease (MAFLD) and ultrasound-based fatty liver disease in relation to endometrial thickness

\begin{tabular}{|c|c|c|c|c|}
\hline & \multicolumn{4}{|c|}{ Liver status } \\
\hline & \multicolumn{2}{|c|}{$\begin{array}{l}\text { Ultrasonic fatty livera }(+) \\
(\mathrm{n}=2663)\end{array}$} & \multicolumn{2}{|l|}{ MAFLD (+) $(n=2543)$} \\
\hline & OR $(95 \% \mathrm{CI})^{\mathrm{b}}$ & $P_{\text {trend }}$ & OR $(95 \% \mathrm{CI})$ & $P_{\text {trend }}$ \\
\hline \multicolumn{5}{|l|}{ Binary model 1} \\
\hline $\begin{array}{l}\text { Endometrial } \\
\text { thickness, mm }\end{array}$ & 1.052 (1.017-1.089) & 0.003 & 1.056 (1.021-1.093) & 0.002 \\
\hline $\mathrm{ET}<3 \mathrm{~mm}$ & 1 (Reference) & 0.025 & 1 (Reference) & 0.018 \\
\hline $3 \mathrm{~mm} \leq \mathrm{ET}<5 \mathrm{~mm}$ & $1.084(0.986-1.192)$ & 0.093 & $1.082(0.983-1.191)$ & 0.106 \\
\hline $\mathrm{ET} \geq 5 \mathrm{~mm}$ & 1.309 (1.052-1.628) & 0.016 & $1.336(1.072-1.665)$ & 0.010 \\
\hline \multicolumn{5}{|l|}{ Binary model 2} \\
\hline Agec $^{c}, y$ & $1.015(1.008-1.022)$ & $<0.001$ & $1.018(1.012-1.025)$ & $<0.001$ \\
\hline $\begin{array}{l}\text { Endometrial } \\
\text { thickness, mm }\end{array}$ & 1.060 (1.024-1.096) & 0.001 & 1.065 (1.029-1.102) & $<0.001$ \\
\hline $\mathrm{ET}<3 \mathrm{~mm}$ & 1 (Reference) & 0.008 & 1 (Reference) & 0.004 \\
\hline $3 \mathrm{~mm} \leq \mathrm{ET}<5 \mathrm{~mm}$ & 1.107 (1.007-1.218) & 0.036 & $1.110(1.008-1.223)$ & 0.034 \\
\hline $\mathrm{ET} \geq 5 \mathrm{~mm}$ & 1.347 (1.082-1.676) & 0.008 & 1.383 (1.109-1.724) & 0.004 \\
\hline
\end{tabular}

Table 5. Multivariable adjusted analysis for BMI in relation to endometrial thickness

\begin{tabular}{|c|c|c|c|c|}
\hline & \multicolumn{4}{|c|}{ Endometrial thickness, $\mathrm{mm}^{\mathrm{b}}$} \\
\hline & \multicolumn{2}{|c|}{$3 \mathrm{~mm} \leq \mathrm{ET}<5 \mathrm{~mm}$} & \multicolumn{2}{|l|}{$\mathrm{ET} \geq 5 \mathrm{~mm}$} \\
\hline & OR $(95 \% \mathrm{CI})$ & $P_{\text {trend }}$ & OR $(95 \% \mathrm{CI})$ & $P_{\text {trend }}$ \\
\hline Age, $y$ & $1.050(1.032-1.068)$ & $<0.001$ & $1.016(0.998-1.035)$ & 0.073 \\
\hline \multicolumn{5}{|c|}{ Body mass index } \\
\hline $\begin{array}{l}\text { Average, } \\
18.5 \leq \mathrm{BMI} \leq 22.9\end{array}$ & $1.337(0.756-2.366)$ & 0.318 & $1.192(0.671-2.118)$ & 0.549 \\
\hline $\begin{array}{l}\text { Overweight, } \\
\text { BMI } \geq 23 \sim 24.9\end{array}$ & $1.795(1.005-3.203)$ & 0.048 & $1.430(0.798-2.563)$ & 0.230 \\
\hline $\begin{array}{l}\text { Obese I, } \\
\mathrm{BMI} \geq 25 \sim 29.9\end{array}$ & $2.458(1.388-4.354)$ & 0.002 & $1.821(1.024-3.238)$ & 0.041 \\
\hline Obese II, BMI $\geq 30$ & 3.409 (1.343-8.654) & 0.010 & $2.562(1.002-6.550)$ & 0.050 \\
\hline
\end{tabular}

\section{Discussion}

Obesity is a very serious public health problem around the world and an important contributing factor for the metabolic syndrome, which is an established risk factor associated with cancer risk and mortality [41], including endometrial cancer [42] and fatty liver disease-related hepatocellular carcinoma
[43]. Relevant research found that obesity-related cancer may be related to MAPK signalling [41]. World Health Organization (WHO) reports recently that about 2 billion (39\%) adults are overweight and over 600 million (13\%) are obese. Another study performed from 1975 to 2014 in 19.2 million adult participants, reported that the age-standardized prevalence of obesity increased from $6.4 \%$ in 1975 to $14.9 \%$ in 2014 in women and both were higher than male [29]. In addition, women may be more susceptible than men to the effects of estrogen.

Obesity and estrogen [44] are the strong risk factor for endometrial cancer $[42,45]$. Also, obesity has been found to increase endometrial thickness independently [46-48] and other pathologies in post-menopausal women through an action on androgen concentrations $[49,50]$. Here, the ET analysis was used to predict the occurrence of endometrial disease and BMI to represent the degree of overweight and obesity. The clinical significance of ET can be applied to investigate endometrial abnormalities in asymptomatic women [51] and can lie in the early detection of endometrial carcinoma [52]. There was evidence that the prevalence of FLD generally increased incrementally with greater BMI [13]. Increased endometrial thickness is associated with estrogen levels [33]. Studies have been reported that there was a positive and significant correlation between BMI of $\geq 30 \mathrm{~kg} / \mathrm{m}^{2}$ and ET, demonstrating the influence of obesity on endometrial thickening $[53,54]$. Two recent studies have demonstrated that surgical menopause results in a significantly increased risk of FLD in women with endometrial cancer [1,31]. Also, treating obesity by bariatric surgery can improve endometrial cancer survivorship [42].

The results of this study indicated a significant correlation between MAFLD and ET without adjusting for any other risk factors using the whole sample. There is a positive correlation between MAFLD and ET in the general population. This significant correlation persisted after adjustment for age. So, we have reason to believe that this study supports that there is a statistical correlation between MAFLD or ultrasonic fatty liver and ET. In addition, we speculate that the ET is closely related to obesity 
and abdominal fat distribution. It is noteworthy to exclude BMI to minimize this as a confounding factor. However, after adjusting for age, multiple logistic did confirm the findings that a significant positive correlation was detected among BMI and ET. This is an important finding of our study and it also highlights the impact of obesity on ET.

The study has several limitations. Most importantly, the limited number of female cheek-up crowd postmenopausal women with imaging examination and metabolic components only restricted conclusions concerning the significance, especially when divided into subgroups. Second, the retrospective study design does not permit to fully reproduction the reasons for an indication of surgical excision like abortion operation in all cases. However, further longitudinal research with larger participants cohorts or meta-analyses of existing surveys is necessary to explore the relationship between MAFLD and the ET.

If postmenopausal women, especially obese people, have developed MAFLD, then a pelvic ultrasound needed to be performed to monitor the ET for detecting early-stage endometrial cancer. Our study also demonstrated the value of controlling obesity and promoting healthy weight in the population. It is therefore an optimal key to improve quality of life and prevent the occurrence of fatty liver disease and gynecological disease worldwide by healthy weight control behaviors. Interestingly, histological improvement in liver biopsies is associated with the extent of weight loss [29]. Unfortunately, to date, none of the pharmacological approaches have provided a real, long-lasting benefit. With the obvious exception of genetics, almost all of the susceptibility factors for fatty liver disease are theoretically modifiable, highlighting the potential impact of education and policy in attenuating the burden of it $[55,56]$. Thus, the cornerstones to the management of this disease are still lifestyle modifications and weight loss [57].

\section{Supplementary Material}

Supplementary figures and tables.

http://www.medsci.org/v18p3082s1.pdf

\section{Acknowledgements}

We thank Dr. Li-ping Liu and Dr. Bo Tu for their help in data recognition and classification regarding ultrasound reports.

\section{Compliance with Ethical Standards}

\section{Ethical approval}

All procedures in studies involving human participants were performed in accordance with the ethical standards of the institutional research committee (the Ethics Committee of the First Affiliated Hospital of Chongqing Medical University) and with the 1964 Helsinki Declaration and its later amendments or comparable ethical standards.

\section{Informed consent}

Written informed consent was waived on account of the retrospective design of the study.

\section{Competing Interests}

The authors have declared that no competing interest exists.

\section{References}

1. Moeini A, Machida H, Takiuchi T, et al. Association of Nonalcoholic Fatty Liver Disease and Venous Thromboembolism in Women With Endometrial Cancer. Clinical and applied thrombosis/hemostasis : official journal of the International Academy of Clinical and Applied Thrombosis/Hemostasis 2017; 23(8): 1018-27.

2. Rinella $\mathrm{M}$, Charlton $\mathrm{M}$. The globalization of nonalcoholic fatty liver disease: Prevalence and impact on world health. Hepatology (Baltimore, Md) 2016; 64(1): 19-22.

3. Eslam M, Newsome PN, Sarin SK, et al. A new definition for metabolic dysfunction-associated fatty liver disease: An international expert consensus statement. Journal of hepatology 2020; 73(1): 202-9.

4. Shiha G, Alswat K, Al Khatry M, et al. Nomenclature and definition of metabolic-associated fatty liver disease: a consensus from the Middle East and north Africa. The lancet Gastroenterology \& hepatology 2021; 6(1): 57-64.

5. Fouad Y, Gomaa A, Semida N, Ghany WA, Attia D. Change from NAFLD to MAFLD increases the awareness of fatty liver disease in primary care physicians and specialists. Journal of hepatology 2021; 74(5): 1254-6.

6. Alem SA, Gaber Y, Abdalla M, Said E, Fouad Y. Capturing patient experience: A qualitative study of change from NAFLD to MAFLD real-time feedback. Journal of hepatology 2021; 74(5): 1261-2.

7. Eslam M, Sanyal AJ, George J. MAFLD: A Consensus-Driven Proposed Nomenclature for Metabolic Associated Fatty Liver Disease. Gastroenterology 2020; 158(7): 1999-2014.e1.

8. Lee H, Lee YH, Kim SU, Kim HC. Metabolic Dysfunction-Associated Fatty Liver Disease and Incident Cardiovascular Disease Risk: A Nationwide Cohort Study. Clinical gastroenterology and hepatology : the official clinical practice journal of the American Gastroenterological Association 2020.

9. Mendez-Sanchez N, Arrese M, Gadano A, et al. The Latin American Association for the Study of the Liver (ALEH) position statement on the redefinition of fatty liver disease. The lancet Gastroenterology \& hepatology 2021; 6(1): 65-72.

10. Spearman CW, Desalegn H, Ocama P, et al. The sub-Saharan Africa position statement on the redefinition of fatty liver disease: From NAFLD to MAFLD. Journal of hepatology 2021; 74(5): 1256-8.

11. Fouad Y, Waked I, Bollipo S, Gomaa A, Ajlouni Y, Attia D. What's in a name? Renaming 'NAFLD' to 'MAFLD'. Liver international : official journal of the International Association for the Study of the Liver 2020; 40(6): 1254-61.

12. Practice Bulletin No. 149: Endometrial cancer. Obstetrics and gynecology 2015; 125(4): 1006-26.

13. Anderson EL, Howe LD, Jones HE, Higgins JP, Lawlor DA, Fraser A. The Prevalence of Non-Alcoholic Fatty Liver Disease in Children and Adolescents: A Systematic Review and Meta-Analysis. PloS one 2015; 10(10): e0140908.

14. Eslam M, Sarin SK, Wong VW, et al. The Asian Pacific Association for the Study of the Liver clinical practice guidelines for the diagnosis and management of metabolic associated fatty liver disease. Hepatology international 2020

15. Brooks RA, Fleming GF, Lastra RR, et al. Current recommendations and recent progress in endometrial cancer. CA: a cancer journal for clinicians 2019; 69(4): $258-79$

16. Braun MM, Overbeek-Wager EA, Grumbo RJ. Diagnosis and Management of Endometrial Cancer. American family physician 2016; 93(6): 468-74.

17. Lin MY, Dobrotwir A, McNally $\mathrm{O}$, Abu-Rustum NR, Narayan $\mathrm{K}$, Role of imaging in the routine management of endometrial cancer. International journal of gynaecology and obstetrics: the official organ of the International Federation of Gynaecology and Obstetrics 2018; 143 Suppl 2(Suppl 2): 109-17.

18. Urick ME, Bell DW. Clinical actionability of molecular targets in endometrial cancer. Nature reviews Cancer 2019; 19(9): 510-21.

19. ACOG Committee Opinion No. 734: The Role of Transvaginal Ultrasonography in Evaluating the Endometrium of Women With Postmenopausal Bleeding. Obstetrics and gynecology 2018; 131(5): e124-e9. 
20. Tofiloska V, Velik-Stefanovska V, Dimitrov G. The Connection between the Endometrial Thickness and the Risk of Endometrial Malignancy in Postmenopausal Women. Open access Macedonian journal of medical sciences 2019; 7(14): 2263-6.

21. Stoenescu V, Novac MB, Dijmarescu L, et al. The Importance of the Correlation between the Ultrasonographic Evaluation of Endometrium and Histopathological Findings in Patients with Endometrial Hyperplasia and Carcinoma. Current health sciences journal 2017; 43(2): 149-52.

22. Langer RD, Pierce JJ, O'Hanlan KA, et al. Transvaginal ultrasonography compared with endometrial biopsy for the detection of endometrial disease. Postmenopausal Estrogen/Progestin Interventions Trial. The New England journal of medicine 1997; 337(25): 1792-8.

23. Saatli B, Yildirim N, Olgan S, Koyuncuoglu M, Emekci O, Saygilı U. The role of endometrial thickness for detecting endometrial pathologies in asymptomatic postmenopausal women. The Australian \& New Zealand journal of obstetrics $\mathcal{E}$ gynaecology 2014; 54(1): 36-40.

24. Van den Bosch T, Van Schoubroeck D, Domali E, et al. A thin and regular endometrium on ultrasound is very unlikely in patients with endometrial malignancy. Ultrasound in obstetrics \& gynecology: the official journal of the International Society of Ultrasound in Obstetrics and Gynecology 2007; 29(6): 674-9.

25. Alcázar JL, Bonilla L, Marucco J, et al. Risk of endometrial cancer and endometrial hyperplasia with atypia in asymptomatic postmenopausal women with endometrial thickness $\geq 11 \mathrm{~mm}$ : A systematic review and meta-analysis. Journal of clinical ultrasound: JCU 2018; 46(9): 565-70.

26. Jacobs I, Gentry-Maharaj A, Burnell M, et al. Sensitivity of transvaginal ultrasound screening for endometrial cancer in postmenopausal women: a case-control study within the UKCTOCS cohort. The Lancet Oncology 2011; 12(1): 38-48.

27. Felix AS, Weissfeld JL, Pfeiffer RM, et al. Endometrial thickness and risk of breast and endometrial carcinomas in the prostate, lung, colorectal and ovarian cancer screening trial. International journal of cancer 2014; 134(4): 954-60.

28. Yamamura S, Eslam M, Kawaguchi T, et al. MAFLD identifies patients with significant hepatic fibrosis better than NAFLD. Liver international: official journal of the International Association for the Study of the Liver 2020; 40(12): 3018-30.

29. Araújo AR, Rosso N, Bedogni G, Tiribelli C, Bellentani S. Global epidemiology of non-alcoholic fatty liver disease/non-alcoholic steatohepatitis: What we need in the future. Liver international: official journal of the International Association for the Study of the Liver 2018; 38 Suppl 1: 47-51.

30. Kodama K, Tokushige K, Hashimoto E, Taniai M, Shiratori K. Hepatic and extrahepatic malignancies in cirrhosis caused by nonalcoholic steatohepatitis and alcoholic liver disease. Alcoholism, clinical and experimental research 2013; 37 Suppl 1: E247-52.

31. Matsuo K, Gualtieri MR, Cahoon SS, et al. Surgical menopause and increased risk of nonalcoholic fatty liver disease in endometrial cancer. Menopause (New York, NY) 2016; 23(2): 189-96.

32. Fouad Y, Elwakil R, Elsahhar M, et al. The NAFLD-MAFLD debate: Eminence vs evidence. Liver international : official journal of the International Association for the Study of the Liver 2021; 41(2): 255-60.

33. Li H, Ran L, Wu H, Xu Z, Wu KN, Kong LQ. A population-based study of the relationship between endometrial thickness and prevalence of breast mass in postmenopausal women. International journal of gynaecology and obstetrics: the official organ of the International Federation of Gynaecology and Obstetrics 2019; 145(3): 306-11.

34. Latenstein CSS, Alferink LJM, Darwish Murad S, Drenth JPH, van Laarhoven C, de Reuver PR. The Association Between Cholecystectomy, Metabolic Syndrome, and Nonalcoholic Fatty Liver Disease: A Population-Based Study. Clinical and translational gastroenterology 2020; 11(4): e00170.

35. Kakati D, Kumar U, Russ $\mathrm{K}$, et al. Cholecystectomy does not worsen progression or outcomes in non-alcoholic fatty liver disease. Translational gastroenterology and hepatology 2020; 5: 3 .

36. Yue $\mathrm{W}$, Sun $\mathrm{X}, \mathrm{Du} \mathrm{T}$. Cholecystectomy versus central obesity or insulin resistance in relation to the risk of nonalcoholic fatty liver disease: the third US National Health and Nutrition Examination Survey. BMC endocrine disorders 2019; 19(1): 95.

37. Duijkers IJ, Klipping C, Verhoeven $\mathrm{CH}$, Dieben TO. Ovarian function with the contraceptive vaginal ring or an oral contraceptive: a randomized study. Human reproduction (Oxford, England) 2004; 19(11): 2668-73.

38. Bulten J, Grefte J, Siebers B, Dieben T. The combined contraceptive vaginal ring (NuvaRing) and endometrial histology. Contraception 2005; 72(5): 362-5.

39. Husby A, Wohlfahrt J, Melbye M. Pregnancy duration and endometrial cancer risk: nationwide cohort study. BMJ (Clinical research ed) 2019; 366: 14693.

40. Alberti KG, Eckel RH, Grundy SM, et al. Harmonizing the metabolic syndrome: a joint interim statement of the International Diabetes Federation Task Force on Epidemiology and Prevention; National Heart, Lung, and Blood Institute; American Heart Association; World Heart Federation; International Atherosclerosis Society; and International Association for the Study of Obesity. Circulation 2009; 120(16): 1640-5.

41. Donohoe F, Wilkinson M, Baxter E, Brennan DJ. Mitogen-Activated Protein Kinase (MAPK) and Obesity-Related Cancer. International journal of molecular sciences 2020; $21(4)$

42. Shafa A, Kumar A, Torres D, McKenzie TJ. Minimally Invasive Hysterectomy and Bariatric Surgery to Improve Endometrial Cancer Survivorship. Obstetrics and gynecology 2019; 134(3): 570-2.
43. Kerr I, Anderson C, Lippman SM. Physical activity, sedentary behaviour, diet, and cancer: an update and emerging new evidence. The Lancet Oncology 2017; 18(8): e457-e71.

44. Sit AS, Modugno F, Hill LM, Martin J, Weissfeld JL. Transvaginal ultrasound measurement of endometrial thickness as a biomarker for estrogen exposure. Cancer epidemiology, biomarkers \& prevention: a publication of the American Association for Cancer Research, cosponsored by the American Society of Preventive Oncology 2004; 13(9): 1459-65.

45. Raglan O, Kalliala I, Markozannes G, et al. Risk factors for endometrial cancer: An umbrella review of the literature. International journal of cancer 2019; 145(7): 1719-30.

46. Schapira DV, Kumar NB, Lyman GH, Cavanagh D, Roberts WS, LaPolla J. Upper-body fat distribution and endometrial cancer risk. Jama 1991; 266(13): 1808-11.

47. Osmers RG, Kuhn W. Endometrial cancer screening. Current opinion in obstetrics \& gynecology 1994; 6(1): 75-9.

48. Siiteri PK. Adipose tissue as a source of hormones. The American journal of clinical nutrition 1987; 45(1 Suppl): 277-82.

49. Serin IS, Ozçelik B, Basbug M, Ozsahin O, Yilmazsoy A, Erez R. Effects of hypertension and obesity on endometrial thickness. European journal of obstetrics, gynecology, and reproductive biology 2003; 109(1): 72-5.

50. Arıkan I, Barut A, Arıkan D, Harma M, Harma M, Bozkurt S. Comparison of serum androgens and endometrial thickness in obese and non-obese postmenopausal women. Journal of the Turkish German Gynecological Association 2010; 11(3): 149-51.

51. Love CD, Muir BB, Scrimgeour JB, Leonard RC, Dillon P, Dixon JM. Investigation of endometrial abnormalities in asymptomatic women treated with tamoxifen and an evaluation of the role of endometrial screening. Journal of clinical oncology: official journal of the American Society of Clinical Oncology 1999; 17(7): 2050-4.

52. Osmers R, Völksen M, Schauer A. Vaginosonography for early detection of endometrial carcinoma? Lancet (London, England) 1990; 335(8705): 1569-71.

53. Rosen MW, Tasset J, Kobernik EK, Smith YR, Johnston C, Quint EH. Risk Factors for Endometrial Cancer or Hyperplasia in Adolescents and Women 25 Years Old or Younger. Journal of pediatric and adolescent gynecology 2019; 32(5): 546-9.

54. Barboza IC, Depes Dde B, Vianna Júnior I, et al. Analysis of endometrial thickness measured by transvaginal ultrasonography in obese patients. Einstein (Sao Paulo, Brazil) 2014; 12(2): 164-7.

55. Shiha G, Korenjak M, Eskridge W, et al. Redefining fatty liver disease: an international patient perspective. The lancet Gastroenterology \& hepatology 2021; 6(1): 73-9.

56. Clayton M, Fabrellas N, Luo J, et al. From NAFLD to MAFLD: Nurse and allied health perspective. Liver international : official journal of the International Association for the Study of the Liver 2021; 41(4): 683-91.

57. Booth FW, Roberts CK, Laye MJ. Lack of exercise is a major cause of chronic diseases. Comprehensive Physiology 2012; 2(2): 1143-211. 